\title{
Quantitative ultrasound screening of bone mineral density on children with short stature
}

\author{
Abdulmoein E. Al-Agha, CABP, FRCPCH, Yousef O. Kabli, MBBS, Melissa G. AlBeiruty, MBBS, \\ Hadeer E. Daftardar, MBBS, Sulaf Z. Alkhattabi, MBBS, Wafa M. Badauod, MBBS, Wejdan A. Bamusa, MBBS.
}

\begin{abstract}
الأهداف : فحص كثافة العظام والعوامل المؤثرة فيه وذلك على على الأطفال الذين الذين

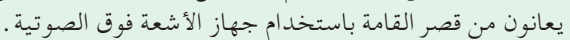

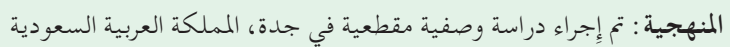

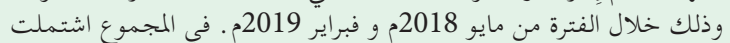

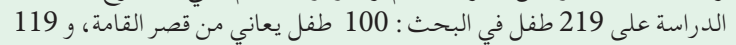

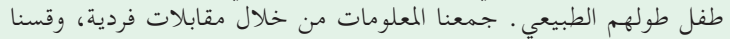

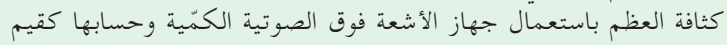
. Z-scores

النتائج : الأطفال ذوي قصر القامة كان لديهم قيم أقل من الأطفال ذوي الطول

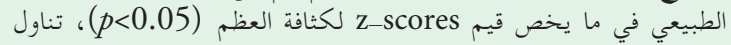

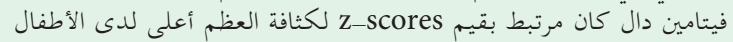
قصار القامة (

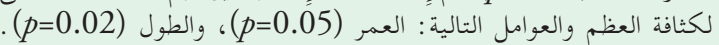

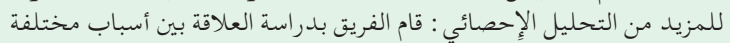

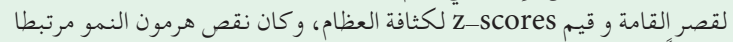
إيجابياً بقيم Z-scores لكثافة العظام (

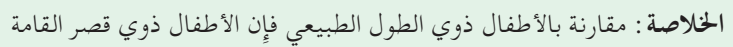

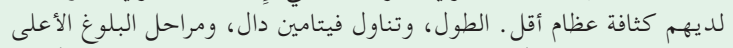

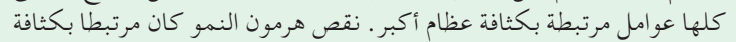

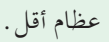

Objectives: To assess bone mineral density (BMD) of children with short stature using quantitative ultrasound (QUS) and compare it to children with normal height.

Methods: We conducted a descriptive, cross-sectional controlled study between May 2018 and February 2019 at various pediatric clinics in Jeddah, Saudi Arabia. In total, 219 children were included: 100 had short stature, and 119 were of normal height. Data were collected from one-on-one interviews, and $\mathrm{BMD}$ was measured using quantitative ultrasound.

Results: Children with short stature had significantly lower BMD z-scores than children with normal height $(p<0.05)$. The use of vitamin D supplements was related to higher BMD z-scores in children with short stature $(p<0.05)$. A significant association was found between higher BMD z-scores, and both age $(p=0.05)$ and height $(p=0.02)$. Through a further division of children with short stature into those with and those without growth hormone deficiencies, we show that growth hormone deficiency was positively associated with lower BMD z-scores; however, the $p$-value was 0.06 .

Conclusions: Compared with children of normal height, those with short stature had lower BMD. Height, vitamin D supplementation, and age were all significantly correlated with higher BMD, while growth hormone deficiency was correlated with lower BMD.

Keywords: bone density, quantitative ultrasound, short stature, pediatric bone

Saudi Med J 2020; Vol. 41 (6): 597-601

doi: 10.15537/smj.2020.6.25126

From the Department of Pediatrics, King Abdulaziz University Hospital, Jeddah, Kingdom of Saudi Arabia.

Received 28th January 2020. Accepted 19th May 2020.

Address correspondence and reprint request to: Dr. Abdulmoein E. Al-Agha, Pediatric Department, King Abdulaziz University Hospital, Jeddah, Kingdom of Saudi Arabia. E-mail:aagha@kau.edu.sa

ORCID ID: https://orcid.org/0000-0002-7168-6447

$\mathrm{B}$ one health is determined by many anthropological and physiological factors. These factors, especially those among children, have been of interest in many researchers during the past decade because of their effects on bone health impact health status in both child- and adult-hood. ${ }^{1-3}$ Normal height is among the factors that show a good correlation with higher bone-mineral density (BMD), whereas short stature is correlated with low BMD even in children with familial 
short stature. ${ }^{3}$ There are multiple ways to assess BMD; however, dual-energy $\mathrm{x}$-ray absorptiometry (DXA) is the most common. ${ }^{4,5}$ Although DXA is precise and reliable for assessing $\mathrm{BMD}$, it is also expensive and involves a small amount of radiation. ${ }^{4}$ An emerging approach for measuring BMD uses quantitative ultrasound (QUS) for screening patients at risk for osteoporosis. Quantitative ultrasound uses high-frequency sound waves to evaluate bone quality. It operates by determining the speed of sound waves regulated by multiple factors, including height, pubertal status, bone architecture, and soft tissue thickness. ${ }^{6}$ Quantitative ultrasound can be used on the distal radius, tibial shaft, calcaneus, and patella. Given its accessibility, affordability, portability, and immediate results, QUS is easier to apply on a wide scale than that of other BMD measuring techniques. ${ }^{6}$

In this study, we assessed the BMD of children with short stature using QUS, and compared them to children with normal height. Furthermore, we also analyzed additional factors associated with both low and high BMD.

Methods. We performed a descriptive, crosssectional study between May 2018 and February 2019 at various pediatric clinics in Jeddah, Saudi Arabia. Before the commencement of this study, ethical approval was obtained from the research ethical committee at King Abdulaziz University and all procedures were conducted in compliance with the Declaration of Helsinki. Written-informed consent was obtained from the parents or guardians of the children. A private room was prepared at the pediatric clinics to interview the patients in the company of their parents or legal guardians.

All children with normal height and those with short stature (defined as a height minus 2 standard deviations from the mean height) of the same age and gender were recruited for the study. After getting their verbal consent to participate, data were collected by interviewing all children and their parents or guardians regarding modifiable factors known to affect BMD, including sun exposure, physical activity, daily milk consumption, dairy product consumption, vitamin D supplementation, consumption of formula milk during the first 2 years of life, and all medications actively used by the participant. Height and anthropometric

Disclosure. Authors have no conflict of interests, and the work was not supported or funded by any drug company. measurements were performed, and BMD was assessed using QUS. The results were collected as z-scores and were explained to the participant' parents/guardians.

Only children between the ages of 2 and 18 years were included in this study. The short stature group included children with different causes of short stature, including growth hormone $(\mathrm{GH})$ deficiency (characterized by the inadequate secretion of $\mathrm{GH}$ from the anterior pituitary gland), low $\mathrm{GH}$ peak levels $(<10 \mathrm{ng} / \mathrm{mL}$ after stimulation), ${ }^{7}$ familial short stature (defined as bone-age appropriate for chronologic age, normal growth, and predicted adult height appropriate for the familial pattern), ${ }^{8}$ idiopathic short stature (defined as having no identifiable disorder of the $\mathrm{GH} /$ insulin-like growth factor axis and no other endocrine, genetic, or organ system disorder), ${ }^{9}$ hypothyroidism (defined as thyroid-stimulating hormone concentrations above the reference range and free thyroxine concentrations below the reference range), ${ }^{10}$ and girls with early puberty (attributable to gonadotropin-releasing hormone $(\mathrm{GnRH})$ agonist). All children had their Tanner stage measured by their parent using a Tanner stage graph provided by the clinic.

The exclusion criteria comprised the presence of metabolic disorders, chronic medical diseases, inflammatory bowel disease, diabetes, and congenital adrenal hyperplasia. Additionally, children who were not able to provide consistent results throughout the QUS screening were excluded. In total, 400 of 500 recruited children were accepted and participated in our study. However, 181 children were removed after applying our exclusion criteria, leaving a total of 219 participants in our study. We divided the cohort into 2 groups, those with short stature $(\mathrm{n}=100)$ and those with normal height $(\mathrm{n}=119)$.

Data entryand statistical analysis was performed using IBM Statistical Package for Social Sciences version 24 (IBM Corp, Armonk, NY, USA). Categorical variables were expressed either in frequency or in proportion. Continuous variables were expressed in range, mean, and standard deviation. Descriptive analysis and frequency assessments were carried out to display the characteristics of the sample such as: age, height, weight, and gender. The relationship between mean BMD z-scores and each categorical variable (gender, Tanner stage, short stature) was assessed using one-way analysis of variance (ANOVA). The relationship between mean BMD z-scores and other continuing variables was studied using Pearson's bivariate correlation, which was used to determine the presence or absence of a significant correlation. Calculated $p$-values less than 0.05 were interpreted to be significant. 
Results. The gender distribution of the children in both groups was almost equal, with the normal height group comprised of $63 \%$ females and the short stature group comprising $55 \%$ males (Table 1 ). The mean ages for the normal height group was 9.4 and the short stature group was 10.4 years. The mean BMD measurements for the normal height group was -1.51 and the short stature group was -1.56 . The mean height for the short stature group was $126 \mathrm{~cm}$ (standard deviation: -2 to $-6.4 \mathrm{~cm}$ ), while that for the normal height group was $129 \mathrm{~cm}$ (standard deviation: -1.8 to $2.6 \mathrm{~cm}$ ).

A significant association was found between short stature and lower BMD $(p=0.000)$. Furthermore, the use of vitamin $\mathrm{D}$ supplementation was common to those with short stature and showed a significant correlation with higher BMD z-scores when compared to those not taking the supplements $(p=0.000)$. Additional analyses of the short stature group revealed a positive association between higher BMD z-scores and both older age $(p=0.05)$ and taller height $(p=0.02)$. Children with short stature due to $\mathrm{GH}$ deficiency showed an association between GH deficiency and lower BMD z-scores when compared to those resulting from other causes; however, the $p$-value was 0.06 (Figure 1 ).

Discussion. We have shown that children with short stature have lower BMD z-scores than children of normal height, highlighting the need of BMD screening in children with short stature. Additional factors found

Table 1 - Descriptive statistics.

\begin{tabular}{lccc}
\hline Variables & \multicolumn{2}{c}{ Range } & Mean \pm SD \\
\hline Group of short stature & & & \\
Age in years & 4.00 & 17.50 & $10.4 \pm 3.64$ \\
Height (cm) & 87.00 & 157.00 & $126.7 \pm 18.04$ \\
Weight (Kg) & 9.50 & 50.00 & $23.6 \pm 8.59$ \\
BMD Z-score & -5.10 & 1.10 & $-1.56 \pm 1.39$ \\
Height SD & -7.70 & -2.00 & $-3.24 \pm 1.16$ \\
Group of normal height & & & \\
Age in years & 2.00 & 17.00 & $9.4 \pm 3$ \\
Height (cm) & 68.00 & 176.00 & $129.6 \pm 125$ \\
Weight (Kg) & 10.00 & 175.00 & $33.9 \pm 20$ \\
BMD Z-score & -4.10 & 1.80 & $-1.51 \pm 1.3$ \\
Height SD & -1.83 & 2.69 & $-0.08 \pm 1.00$ \\
\hline
\end{tabular}

to contribute to the abnormal BMD in children with short stature included height, GH deficiency, and pubertal stage. Furthermore, GH deficiency and the use of $\mathrm{GnRH}$ agonists was associated with the lowest BMD among children with short stature, and can therefore be considered as risk factors. Growth hormone has a major role in the process of bone formation. ${ }^{11}$ The absence or deficiency of $\mathrm{GH}$ result inhibits the remodeling process; thereby, leading to the gradual loss of BMD, as well as short stature, and slow bone maturation.

Children who have experienced early puberty and are using a GnRH agonist are at risk for lower BMD z-scores than their peers. A review performed in the United States found that these subjects have low BMD scores. Furthermore, the data from this study suggested that BMD should be carefully monitored in adolescents taking GnRH agonists, ${ }^{12}$ In our study, those who were receiving $\mathrm{GnRH}$ agonist treatment had lower BMD z-scores than those with other causes for short stature. This can be attributed to the suppressing effect on gender hormones, which slows the bone-remodeling process. ${ }^{13}$ The sample recruited for our study included children with short stature due to causes other than GH deficiency. These diseases also contributed to low BMD. With hypothyroidism, bone metabolism and mineral metabolism are accelerated by thyroid hormones. Therefore, hormone replacement therapy can cause decreased bone density. However, synthetic thyroid hormone use for longer than a year is required to achieve a significant effect. ${ }^{14,15}$ Previous results have shown that with adequate thyroxin replacement and effective vitamin $\mathrm{D}$ treatment, the effects on bone can be avoided. ${ }^{16}$

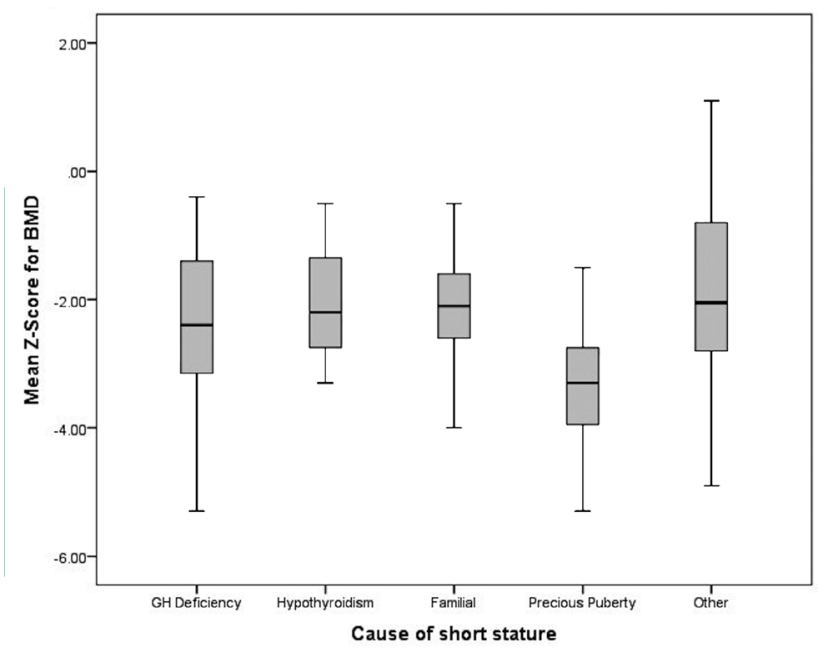

Figure 1 - Mean z-scores for different causes of short stature plotted as a boxplot. 
Familial short stature can be the result of genetic factors. Furthermore, bone density has been reported to be linked with family history. A study involving 2812 Korean adolescents found significant associations between the BMD values of offspring and the BMD of their parents. Recent genome-wide association studies have made great advances in identifying 62 significant genome-wide loci associated with low bone mass and osteoporotic fractures. ${ }^{17}$

Pubertal gender hormones (estradiol in females and testosterone in males) play important roles in bone mass acquisition. They also have a profound influence on longitudinal bone growth and bone-mineral build-up because they are essential for normal skeletal development and the achievement of peak-bone mass with appropriate timing. ${ }^{18}$ In healthy individuals, particularly females, pubertal levels of estradiol increase cortical bone thickness by directly increasing bone density and regulating bone remodeling. ${ }^{19}$ Moreover, androgens (either directly or by aromatization to estrogen) have a huge impact on bone strength because they regulate osteoblast activity through a faster, non-genomic mechanism using their receptors on the osteoblast cell surface. ${ }^{20}$ Our findings revealed higher BMD scores with higher Tanner stages, indicating that longer exposure to pubertal hormones is significantly associated with greater BMD z-scores and therefore, higher BMD. Similarly, a previous study performed in Lebanon on 335 healthy school children reported significant increases in bone mass parameters across different Tanner stages. This might have been because of effects of gender hormones throughout the more mature Tanner stages. ${ }^{21}$

A European multicenter study performed on a cohort of 371 children (aged 6 to 23 years) found that short children have lower BMD than their age-matched peers, even if their smaller bones are completely normal. ${ }^{11}$ Indeed, a smaller study performed in Venezuela found that body size and maturation were major determinants of BMD. ${ }^{22}$ Furthermore, a large Egyptian study of 4002 adolescents concluded that BMD is significantly lower among short stature individuals compared with those of normal height. ${ }^{23}$ Our findings are in agreement with previous studies, showing a significant association between short stature and lower BMD. In addition, we also found a positive association between height and higher BMD z-scores in short stature individuals.

Utilizing QUS as a measurement of BMD has been an established modality of BMD measurements. Although this method is well studied and has a clear role in adults, its use in pediatrics is still in need for further studies in order to refine the best methods for assessing bone strength in children. ${ }^{24}$

Study limitations. The paucity of studies investigating BMD using QUS screening in healthy populations of children within the gulf and middle-east regions makes it difficult to comparatively analyze our data. There is also a paucity of recent worldwide studies investigating BMD with QUS in healthy populations. A previous study using DXA to measure BMD in short stature children found that after 4 years most participants with previously abnormal results moved to within the normal range. The research team concluded that these children are often small for their age and therefore a low bone density may simply reflect a small body size. ${ }^{25}$ In future studies, it will be important to perform longitudinal studies using QUS to assess BMD over time in short stature individuals. Furthermore, as not all of the children in this previous study regained normal BMD, it is essential to carry out follow up studies specifically in these children.

In conclusion, our results show that quantitative ultrasound can be used for screening purposes and for easier assessment in children of high risk for low BMD. Further studies are necessary to identify these high risk children in order to provide early screening and management approaches. In addition, modifiable factors, such as nutritional status and vitamin D supplementation, require further study to confirm if they can improve BMD and bone health among children with short stature.

Acknowledgment. The research team would like to thank Editage (www.editage.com) for the English language editing.

\section{References}

1. Szadek LL, Scharer K. Identification, prevention, and treatment of children with decreased bone mineral density. J Pediatr Nurs 2014; 29: e3-14.

2. Monge MC. Optimizing bone health in adolescents. Curr Opin Obstet Gynecol 2018; 30: 310-315.

3. Ward LM, Konji VN, Ma J. The management of osteoporosis in children. Osteoporos Int 2016; 27: 2147-2179.

4. Ali GY, Abdelbary EE, Albuali WH, AboelFetoh NM, AlGohary EH, AboelFetoh NM, et al. Bone mineral density $\&$ bone mineral content in Saudi children, risk factors and early detection of their affection using dual-emission $\mathrm{x}$-ray absorptiometry (DEXA) scan. Egyptian Pediatric Association Gazette 2017; 65: 65-71.

5. Wasserman H, O’Donnell JM, Gordon CM. Use of dual energy x-ray absorptiometry in pediatric patients. Bone 2017; 104: 84-90. 
6. Bachrach LK, Gordon CM; Section on Endocrinology. Bone densitometry in children and adolescents. Pediatrics 2016; 138 : e20162398.

7. Chinoy A, Murray PG. Diagnosis of growth hormone deficiency in the paediatric and transitional age. Best Pract Res Clin Endocrinol Metab 2016; 30: 737-747.

8. Hussein A, Farghaly H, Askar E, Metwalley K, Saad K, Zahran A, et al. Etiological factors of short stature in children and adolescents: experience at a tertiary care hospital in Egypt. Ther Adv Endocrinol Metab 2017; 8: 75-80.

9. Deodati A, Cianfarani S. The rationale for growth hormone therapy in children with short stature. J Clin Res Pediatr Endocrinol 2017; 9 Suppl 2: 23-32.

10. Chaker L, Bianco AC, Jonklaas J, Peeters RP. Hypothyroidism. Lancet 2017; 390: 1550-1562.

11. Spagnoli A, Rosenfeld RG. The mechanisms by which growth hormone brings about growth. The relative contributions of growth hormone and insulin-like growth factors. Endocrinol Metab Clin North Am 1996; 25: 615-631.

12. Karakaş NM, Tulgar Kınık S, Özdemir B, Muratoğlu Şahin N, Tekindal MA, Haberal A. Congenital hypothyroidism and bone remodeling cycle. J Clin Res Pediatr Endocrinol 2017; 9: 106-110.

13. Divasta AD, Laufer MR, Gordon CM. Bone density in adolescents treated with a GnRH agonist and add-back therapy for endometriosis. J Pediatr Adolesc Gynecol 2007; 20: 293-297.

14. Kenkre JS, Bassett J. The bone remodelling cycle. Ann Clin Biochem 2018; 55: 308-327.

15. Mendonça Monteiro de Barros G, Madeira M, Vieira Neto L, de Paula Paranhos Neto F, Carvalho Mendonça LM, Corrêa Barbosa Lima I, et al. Bone mineral density and bone microarchitecture after long-term suppressive levothyroxine treatment of differentiated thyroid carcinoma in young adult patients. J Bone Miner Metab 2016; 34: 417-421.
16. Bianchi ML, Leonard MB, Bechtold S, Högler W, Mughal $\mathrm{MZ}$, Schönau E, et al. International Society for Clinical Densitometry. Bone health in children and adolescents with chronic diseases that may affect the skeleton: the 2013 ISCD Pediatric Official Positions. J Clin Densitom 2014; 17: 281-294.

17. Almeida M, Laurent MR, Dubois V, Claessens F, O'Brien CA, Bouillon R, et al. Estrogens and androgens in skeletal physiology and pathophysiology. Physiol Rev 2017; 97: 135-187.

18. Choi HS, Park JH, Kim SH, Shin S, Park MJ. Strong familial association of bone mineral density between parents and offspring: KNHANES 2008-2011. Osteoporos Int 2017; 28: 955-964.

19. Wasserman H, Gordon CM. Bone mineralization and fracture risk assessment in the pediatric population [Internet]. J Clin Densitom 2017; 20: 389-396.

20. Khosla S, Monroe DG. Regulation of bone metabolism by sex steroids. Cold Spring Harb Perspect Med 2018; 8: a031211.

21. Remer T, Boye KR, Hartmann M, Neu CM, Schoenau E, Manz $\mathrm{F}$, et al. Adrenarche and bone modeling and remodeling at the proximal radius: weak androgens make stronger cortical bone in healthy children. J Bone Miner Res 2003; 18: 1539-1546.

22. Schoenau E, Land C, Stabrey A, Remer T, Kroke A. The bone mass concept: problems in short stature. Eur J Endocrinol 2004; 151 Suppl 1: S87-S91.

23. Zemel BS, Leonard MB, Kelly A, Lappe JM, Gilsanz V, Oberfield $S$, et al. Height adjustment in assessing dual energy $\mathrm{x}$-ray absorptiometry measurements of bone mass and density in children. J Clin Endocrinol Metab 2010; 95: 1265-1273.

24. Mora S, Pitukcheewanont P, Kaufman FR, Nelson JC, Gilsanz $\mathrm{V}$. Biochemical markers of bone turnover and the volume and the density of bone in children at different stages of sexual development. J Bone Miner Res 1999; 14: 1664-1671.

25. Gallagher, P., Snow, A., Roche, E., O’Mullane, E., \& Hoey, H. Bone Mineral Density Adjustment in Children with Short Stature. Pediatric Research 2010; 68: 544. 